\title{
The evaluation of the positioning accuracy of the EGNOS and DGPS systems based on the long-term measurements in the years 2006-2014
}

\begin{abstract}
The DGPS (Differential GPS) and EGNOS (European Geostationary Navigation Overlay Service) systems belong to a group of systems supporting the global satellite system GPS (Global Positioning System). These systems have significantly better navigation performance than GPS and, therefore, they are widely used in the maritime, civil and air navigation. The analysis of the positioning accuracy of GPS leads to the conclusion: from year to year the accuracy of the positioning determination increases. The effect of the permanent increasing of the GPS positioning accuracy is the parallel increasing of the positioning accuracies of all the supporting systems. In connection with the constant improvement of the precision characteristics of the above mentioned systems on one hand and the fact, that the users do not possess the current information about the actual status of these characteristics on the other hand, it is reasonable to conduct the periodical research in this area. For that purpose the long-term measurement campaigns were realized in the years 2006-2014; the values of measures, describing the positioning accuracies obtained by both systems, were determined on the basis of those campaigns.
\end{abstract}

Keywords: DGPS, EGNOS, GPS, positioning accuracy, long-term measurement campaigns

\section{Introduction}

The positioning accuracy of GPS depends on the value of a selected Dilution of Precision (DOP) and the User Equivalent Range Error (UERE), which consists of the User Range Error (URE) (Y. Wang, R. Li 2013), as well as of the User Equipment Error (UEE). The value of UEE for the equipment from the 80 s of the last century was typically $5.5 \mathrm{~m}(\mathrm{p}=0.95)$, while nowadays is $1.6 \mathrm{~m}(p=0.95)$ (U.S. DoD 2008). Accordingly, the pattern for the positioning accuracy may be represented as the following formula (P. Grall, C. Specht 2011):

$$
\mathrm{DRMS}=\mathrm{UERE} \cdot \mathrm{DOP}=\sqrt{\left(\mathrm{URE}^{2}+\mathrm{UEE}^{2}\right)} \cdot \mathrm{DOP}(1)
$$

Where:

DRMS - Distance Root Mean Square (horizontal, vertical, spatial) depends on a selected Dilution of Precision (DOP)

UERE - User Equivalent Range Error

URE - User Range Error

UEE - User Equipment Error
DOP - a suitable geometric factor of the satellite position which is relative to the equipment: GDOP, PDOP, HDOP, VDOP, TDOP (Dilution of Precision)

The equation (1) for the positioning accuracy of coordinates for the GPS system takes the simplified form, which is adequate and flexible for many applications. It is correct, because all the pseudorange measurement errors are normally distributed (Gaussian distribution). The chart below (fig. 1) presents the changes in the value of the Twice Distance Root Mean Square Error (2DRMS) 2D for the GPS system $(p=0.95)$ as a function of the variable value URE (B.K. Bailey 2014), assuming UEE amounting to $0.8 \mathrm{~m}$ (RMS) and the factor HDOP, which is equal 1.5 .

From year to year the positioning accuracy of GPS increases and, thus, the positioning accuracies of the systems supporting it (DGPS and EGNOS) also increase. To achieve this, the numerous tests concerning the evaluation of the positioning accuracies of DGPS and EGNOS have been fulfilled in Poland. The 
long-term measurement campaigns, carried out in 2006 and 2009, have shown that the both systems have much better characteristics of accuracy than the GPS system (M. Dziewicki, C. Specht 2009; M. Mięsikowski and others relation to any dimension: space or plane. In order to determine the statistics of positioning errors in navigation, there are three types of accuracy (C. Specht 2007b; U.S. DoD and others 2012):

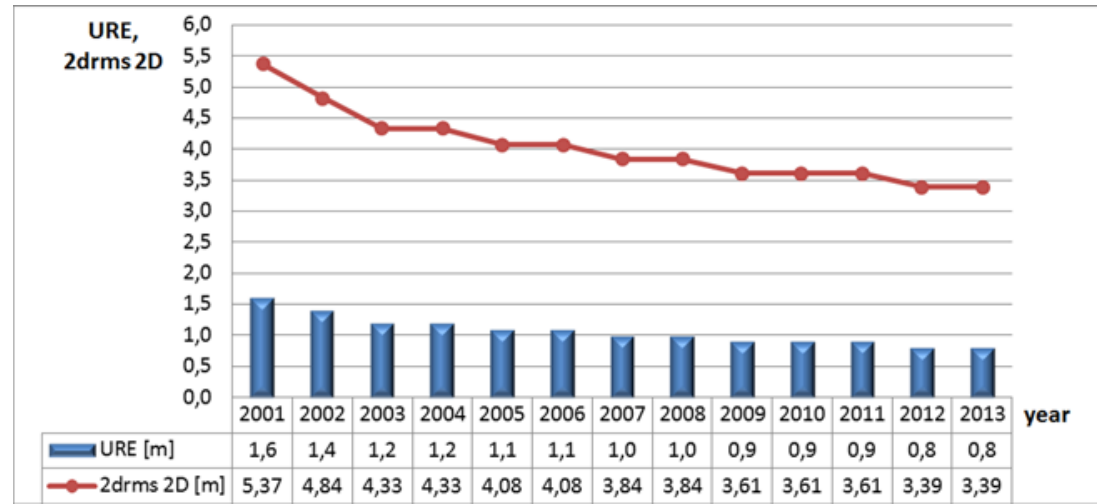

Fig. 1. Value of the Twice Distance Root Mean Square Error (2DRMS) 2D for the GPS system, dependent on URE from 2001-2013 (C. Specht 2015). The URE value was estimated upon (B.K. Bailey 2014)

2006; C. Specht 2007a; C. Specht 2011). For the civilian users of this system the positioning accuracy should not exceed $9 \mathrm{~m}(\mathrm{p}=0.95)$ in the horizontal plane and $15 \mathrm{~m}(\mathrm{p}=0.95)$ in the vertical plane (U.S. DoD 2008). The archived measurements, as well as those made in 2014, are based on the same calculation algorithm in the software Mathcad 15. The content of this article will be a comparative analysis of the positioning accuracies of coordinates within the DGPS and EGNOS systems which have been carried out in the recent years and based on the long-term measurement campaigns.

\section{Types and measures of the positioning accuracy}

The basic navigation characteristic feature of each positioning system is the positioning accuracy. This article attempts to assess the changes in the value of this parameter over the last 8 years. The positioning accuracy means the degree to which the statistics of the measured positions of coordinates are consistent with the actual, real values, or those, which we take for real. A measure of the positioning accuracy is its error, which can be assessed in
- Predictable accuracy is the positioning accuracy expressed in geodetic coordinate system, associated with a model of the Earth - ellipsoid; it informs about the statistical distribution of the positions, which were measured by the system, in relation to the actual values in the system of coordinates, which are used by the system;

- Repeatable accuracy is the positioning accuracy with which the system allows the user to return to a predetermined position within the system of coordinates, which are specific for this system; it informs about the statistical distribution of the positions in relation to its value, which is arbitrarily determinate and most often is considered to be an average position from a measurement series;

- Relative accuracy is the positioning accuracy, which is relative to another user of the same system, at the same time and on the same system of coordinates.

The basic measurements of the positioning accuracy of coordinates, which are used in the wider navigation, are shown in the table 1 (NovAtel Positioning Leadership 2003; F. van Diggelen 2007; B. Whelan, J. Taylor 2013). 
Tab.1. Selected measures of the positioning accuracy

\begin{tabular}{|c|c|c|c|c|}
\hline $\begin{array}{l}\text { The measure } \\
\text { of accuracy }\end{array}$ & $\begin{array}{l}\text { Dimen- } \\
\text { sion }\end{array}$ & Probability & Formula & Definition \\
\hline RMS & 1D & $68.3 \%$ & $R M S=\sqrt{\frac{\sum_{i=1}^{n} \sigma_{i}^{2}}{n-1}}$ & $\begin{array}{l}\text { The standard } \\
\text { deviation of the mean } \\
\text { square error, which is } \\
\text { relative to } \varphi, \lambda \text { or } h\end{array}$ \\
\hline \multirow{2}{*}{ DRMS } & 2D & \multirow{2}{*}{$63.2-68.3 \%$} & $\operatorname{DRMS}(2 \mathrm{D})=\sqrt{\left(\sigma_{\varphi}\right)^{2}+\left(\sigma_{\lambda}\right)^{2}}$ & \multirow{2}{*}{$\begin{array}{c}\text { The root mean square } \\
\text { error sum of squares, } \\
\text { which is relative } \\
\text { to } \varphi, \lambda,(\mathrm{h})\end{array}$} \\
\hline & $3 \mathrm{D}$ & & $\operatorname{DRMS}(3 \mathrm{D})=\sqrt{\left(\sigma_{\varphi}\right)^{2}+\left(\sigma_{\lambda}\right)^{2}+\left(\sigma_{\mathrm{h}}\right)^{2}}$ & \\
\hline \multirow{2}{*}{ 2DRMS } & $2 \mathrm{D}$ & \multirow{2}{*}{$95.4-98.2 \%$} & $2 \mathrm{DRMS}(2 \mathrm{D})=2 \cdot \sqrt{\left(\sigma_{\varphi}\right)^{2}+\left(\sigma_{\lambda}\right)^{2}}$ & \multirow{2}{*}{$\begin{array}{l}\text { Twice the DRMS } \\
\text { (2DRMS) }\end{array}$} \\
\hline & $3 \mathrm{D}$ & & $2 \mathrm{DRMS}(3 \mathrm{D})=2 \cdot \sqrt{\left(\sigma_{\varphi}\right)^{2}+\left(\sigma_{\lambda}\right)^{2}+\left(\sigma_{h}\right)^{2}}$ & \\
\hline CEP & $2 \mathrm{D}$ & $50 \%$ & $\mathrm{CEP}=0.589 \cdot\left(\sigma_{\varphi}+\sigma_{\lambda}\right)$ & $\begin{array}{l}\text { The radius of circle } \\
\text { centered at the true } \\
\text { position, containing } \\
\text { the position estimate } \\
\text { with probability of } 50 \%\end{array}$ \\
\hline SEP & $3 \mathrm{D}$ & $50 \%$ & $\mathrm{SEP}=0.513 \cdot\left(\sigma_{\varphi}+\sigma_{\lambda}+\sigma_{\mathrm{h}}\right)$ & $\begin{array}{l}\text { The radius of sphere } \\
\text { centered at the true } \\
\text { position, containing } \\
\text { the position estimate } \\
\text { with probability of } 50 \%\end{array}$ \\
\hline \multirow{2}{*}{ R68 } & $2 \mathrm{D}$ & \multirow{2}{*}{$68 \%$} & $R 68(2 D)=1.28 \cdot C E P$ & \multirow{2}{*}{$\begin{array}{l}\text { The radius of circle } \\
\text { (sphere) centered } \\
\text { at the true position, } \\
\text { containing the position } \\
\text { estimate with } \\
\text { probability of } 68 \%\end{array}$} \\
\hline & 3D & & $\mathrm{R} 68(3 \mathrm{D})=0.59 \cdot \mathrm{SEP}$ & \\
\hline \multirow[b]{2}{*}{ R95 } & $2 \mathrm{D}$ & \multirow[b]{2}{*}{$95 \%$} & $\mathrm{R} 95(2 \mathrm{D})=2.08 \cdot \mathrm{CEP}$ & \multirow{2}{*}{$\begin{array}{l}\text { The radius of circle } \\
\text { (sphere) centered } \\
\text { at the true position, } \\
\text { containing the position } \\
\text { estimate with } \\
\text { probability of } 95 \%\end{array}$} \\
\hline & $3 \mathrm{D}$ & & $\mathrm{R} 95(3 \mathrm{D})=1.04 \cdot \mathrm{SEP}$ & \\
\hline \multicolumn{5}{|c|}{$\begin{array}{ll}\text { Where: } & \sigma_{\varphi}-\text { standard deviation of geodetic (geographical) latitude } \\
& \sigma_{\lambda}-\text { standard deviation of geodetic (geographical) longitude } \\
& \sigma_{\mathrm{h}}-\text { standard deviation of ellipsoidal height }\end{array}$} \\
\hline
\end{tabular}

\section{Measurement evaluation of the DGPS and EGNOS systems accuracy}

\subsection{General assumptions of the research}

Due to the changing values of errors of the DGPS and EGNOS positioning accuracy there were three long-term measurement campaigns carried out over 2006-2014 (H. Śniegocki and others 2014):
- The first measurement campaign took place in March 2006. During that campaign $1,774,705$ measurements were recorded respectively for EGNOS and 2,187,842 for DGPS with a sampling frequency of $1 \mathrm{~s}$;

- The second measurement campaign took place in July and August 2009. During that campaign 214,842 measurements were recorded for DGPS with a sampling frequency of $1 \mathrm{~s}$; 
Tab. 2. The accuracy characteristics of DGPS based on measurements in 3 campaigns: 2006, 2009 and 2014

\begin{tabular}{|c|c|c|c|c|c|c|}
\hline \multirow{2}{*}{$\begin{array}{c}\text { Statistics of position } \\
\text { error }\end{array}$} & \multicolumn{2}{|c|}{ DGPS 2006 } & \multicolumn{2}{c|}{ DGPS 2009 } & \multicolumn{2}{c|}{ DGPS 2014 } \\
\cline { 2 - 7 } & $\begin{array}{c}\text { Repeatable } \\
\text { accuracy }\end{array}$ & $\begin{array}{c}\text { Predictable } \\
\text { accuracy }\end{array}$ & $\begin{array}{c}\text { Repeatable } \\
\text { accuracy }\end{array}$ & $\begin{array}{c}\text { Predictable } \\
\text { accuracy }\end{array}$ & $\begin{array}{c}\text { Repeatable } \\
\text { accuracy }\end{array}$ & $\begin{array}{c}\text { Predictable } \\
\text { accuracy }\end{array}$ \\
\hline $\begin{array}{c}\text { Number } \\
\text { of measurement }\end{array}$ & \multicolumn{2}{|c|}{$2,187,842$} & \multicolumn{2}{c|}{214,842} & \multicolumn{2}{c|}{951,698} \\
\hline$R M S(\varphi)$ & $0.78 \mathrm{~m}$ & $0.81 \mathrm{~m}$ & $0.12 \mathrm{~m}$ & $0.13 \mathrm{~m}$ & $0.37 \mathrm{~m}$ & $0.40 \mathrm{~m}$ \\
\hline$R M S(\lambda)$ & $0.61 \mathrm{~m}$ & $0.62 \mathrm{~m}$ & $0.16 \mathrm{~m}$ & $0.17 \mathrm{~m}$ & $0.25 \mathrm{~m}$ & $0.26 \mathrm{~m}$ \\
\hline$R M S(h)$ & $1.43 \mathrm{~m}$ & $1.43 \mathrm{~m}$ & $0.33 \mathrm{~m}$ & $0.34 \mathrm{~m}$ & $0.60 \mathrm{~m}$ & $0.60 \mathrm{~m}$ \\
\hline$D R M S(2 D)$ & $0.99 \mathrm{~m}$ & $1.02 \mathrm{~m}$ & $0.20 \mathrm{~m}$ & $0.21 \mathrm{~m}$ & $0.44 \mathrm{~m}$ & $0.48 \mathrm{~m}$ \\
\hline $2 D R M S(2 D)$ & $1.98 \mathrm{~m}$ & $2.04 \mathrm{~m}$ & $0.40 \mathrm{~m}$ & $0.42 \mathrm{~m}$ & $0.88 \mathrm{~m}$ & $0.96 \mathrm{~m}$ \\
\hline$D R M S(3 D)$ & $1.74 \mathrm{~m}$ & $1.76 \mathrm{~m}$ & $0.39 \mathrm{~m}$ & $0.40 \mathrm{~m}$ & $0.75 \mathrm{~m}$ & $0.77 \mathrm{~m}$ \\
\hline$C E P(2 D)$ & $0.78 \mathrm{~m}$ & $0.83 \mathrm{~m}$ & $0.16 \mathrm{~m}$ & $0.16 \mathrm{~m}$ & $0.33 \mathrm{~m}$ & $0.36 \mathrm{~m}$ \\
\hline$R 68(2 D)$ & $1.01 \mathrm{~m}$ & $1.06 \mathrm{~m}$ & $0.21 \mathrm{~m}$ & $0.21 \mathrm{~m}$ & $0.43 \mathrm{~m}$ & $0.47 \mathrm{~m}$ \\
\hline$R 95(2 D)$ & $1.77 \mathrm{~m}$ & $1.79 \mathrm{~m}$ & $0.39 \mathrm{~m}$ & $0.40 \mathrm{~m}$ & $0.75 \mathrm{~m}$ & $0.83 \mathrm{~m}$ \\
\hline$S E P(3 D)$ & $1.35 \mathrm{~m}$ & $1.39 \mathrm{~m}$ & $0.29 \mathrm{~m}$ & $0.38 \mathrm{~m}$ & $0.55 \mathrm{~m}$ & $0.59 \mathrm{~m}$ \\
\hline$R 68(3 D)$ & $1.74 \mathrm{~m}$ & $1.77 \mathrm{~m}$ & $0.39 \mathrm{~m}$ & $0.51 \mathrm{~m}$ & $0.72 \mathrm{~m}$ & $0.76 \mathrm{~m}$ \\
\hline$R 95(3 D)$ & $3.02 \mathrm{~m}$ & $3.04 \mathrm{~m}$ & $1.00 \mathrm{~m}$ & $1.20 \mathrm{~m}$ & $1.39 \mathrm{~m}$ & $1.40 \mathrm{~m}$ \\
\hline
\end{tabular}

Tab. 3. The accuracy characteristics of EGNOS based on measurements in 2 campaigns: 2006 and 2014

\begin{tabular}{|c|c|c|c|c|}
\hline \multirow{2}{*}{ Statistics of position error } & \multicolumn{2}{|c|}{ EGNOS 2006 } & \multicolumn{2}{c|}{ EGNOS 2014 } \\
\cline { 2 - 5 } & $\begin{array}{c}\text { Repeatable } \\
\text { accuracy }\end{array}$ & $\begin{array}{c}\text { Predictable } \\
\text { accuracy }\end{array}$ & $\begin{array}{c}\text { Repeatable } \\
\text { accuracy }\end{array}$ & $\begin{array}{c}\text { Predictable } \\
\text { accuracy }\end{array}$ \\
\hline Number of measurement & \multicolumn{2}{|c|}{$1,774,705$} & \multicolumn{2}{c|}{927,553} \\
\hline$R M S(\varphi)$ & $3.52 \mathrm{~m}$ & $3.74 \mathrm{~m}$ & $0.38 \mathrm{~m}$ & $1.61 \mathrm{~m}$ \\
\hline$R M S(\lambda)$ & $2.28 \mathrm{~m}$ & $2.33 \mathrm{~m}$ & $0.23 \mathrm{~m}$ & $0.29 \mathrm{~m}$ \\
\hline$R M S(h)$ & $6.22 \mathrm{~m}$ & $6.51 \mathrm{~m}$ & $0.69 \mathrm{~m}$ & $1.09 \mathrm{~m}$ \\
\hline$D R M S(2 D)$ & $4.19 \mathrm{~m}$ & $4.41 \mathrm{~m}$ & $0.45 \mathrm{~m}$ & $1.64 \mathrm{~m}$ \\
\hline $2 D R M S(2 D)$ & $8.39 \mathrm{~m}$ & $8.82 \mathrm{~m}$ & $0.90 \mathrm{~m}$ & $3.27 \mathrm{~m}$ \\
\hline$D R M S(3 D)$ & $7.50 \mathrm{~m}$ & $7.87 \mathrm{~m}$ & $0.82 \mathrm{~m}$ & $1.97 \mathrm{~m}$ \\
\hline$C E P(2 D)$ & $1.67 \mathrm{~m}$ & $2.36 \mathrm{~m}$ & $0.30 \mathrm{~m}$ & $1.52 \mathrm{~m}$ \\
\hline$R 68(2 D)$ & $2.28 \mathrm{~m}$ & $2.99 \mathrm{~m}$ & $0.40 \mathrm{~m}$ & $1.68 \mathrm{~m}$ \\
\hline$R 95(2 D)$ & $7.64 \mathrm{~m}$ & $7.62 \mathrm{~m}$ & $0.84 \mathrm{~m}$ & $2.31 \mathrm{~m}$ \\
\hline$S E P(3 D)$ & $2.80 \mathrm{~m}$ & $3.90 \mathrm{~m}$ & $0.51 \mathrm{~m}$ & $1.75 \mathrm{~m}$ \\
\hline$R 68(3 D)$ & $3.96 \mathrm{~m}$ & $4.91 \mathrm{~m}$ & $0.66 \mathrm{~m}$ & $1.99 \mathrm{~m}$ \\
\hline$R 95(3 D)$ & $12.86 \mathrm{~m}$ & $13.44 \mathrm{~m}$ & $1.65 \mathrm{~m}$ & $2.90 \mathrm{~m}$ \\
\hline
\end{tabular}


- The third measurement campaign took place in April and May 2014. During that campaign 927,553 measurements were recorded respectively for EGNOS and 951,698 measurements for DGPS with a sampling frequency of $1 \mathrm{~s}$.

The aim of the measurements was to determine the positioning accuracy of $2 D$ and $3 D$ coordinates of both systems. Reference Station DGPS Rozewie generated the RTCM message (type 9-3), transmitting the pseudorange corrections to the receiver of one frequency located in the port of Gdynia. It was a reference point with the ellipsoidal coordinates, which make up respectively: $\mathrm{B}=54^{\circ} 31.75524^{\prime} \mathrm{N}$, $\mathrm{L}=18^{\circ} 33.57418^{\circ} \mathrm{E}, \mathrm{H}=68.07 \mathrm{~m}$, all the measurements for EGNOS and DGPS were relative to that reference point. The following minimum requirements for implementation the measurements were accepted:

- frequency measurements $\mathrm{L} 1$;

- topocentric height $>5^{\circ}$;

- level of signal strength min. $40 \mathrm{~dB} \mu \mathrm{V}$ and signal-to-noise ratio min. $19 \mathrm{~dB}$ for DGPS;

- geometric factor PDOP for the elevation angle (masking) of the accepted satellites $<10^{\circ}$;

- geometric factor HDOP for the elevation angle (masking) of the accepted satellites $<6^{\circ}$;

- data recoding format - standard NMEA-0183 (communiqué GGA).

The figure 2 presents the location of the measurements spot - the radio beacon of the Port of Gdynia.

\subsection{Method of compiling the data}

Obtaining the data about the coordinates' positions of sets is the initial stage of the research implementation. The vast majority of modern manufactured sets of DGPS and EGNOS allows you to store the data in an automatic way. The manufacturers use two basic strategies of data saving. The first one allows you to save the measured data in a proprietary standard set by a manufacturer. This format makes it impossible to convert the recorded data into the text files in the formats accessible to the user. In this case the data processing is possible only with the use of special (dedicated) software. The second group is a group of sets having the ability to save the measurement data in a form of the text files with the defined data formats

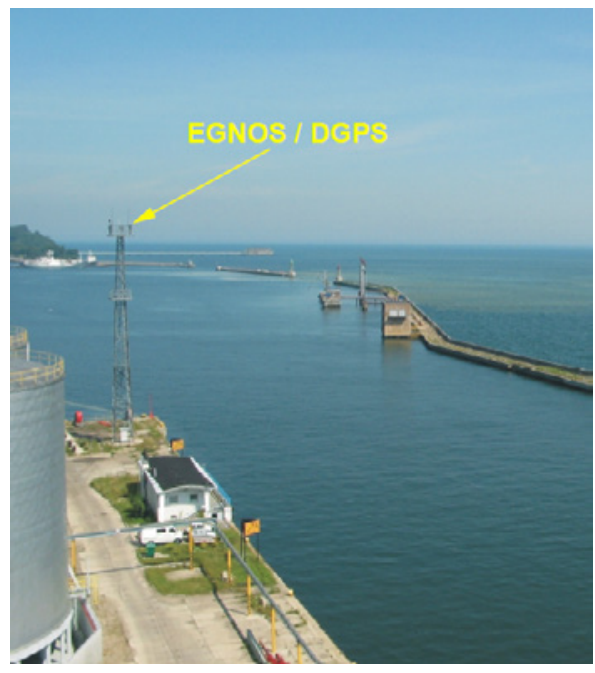

Fig. 2. Location of the measurements spot - the radio beacon of the Port of Gdynia

automatically. The most frequently used data recording format is the National Maritime Electronic Association standard (NMEA), in which the message dedicated to the saving of coordinates called "Global Positioning System Fix Data" (GGA) is used. Data important from the point of view of the positioning accuracy are indicated in orange (fig. 3).

The latitude and longitude presented for measuring the angles (curvilinear) prevent the determination of errors for the individual measurements. For this purpose, it is necessary to project the individual measurements from the surface of the rotational ellipsoid WGS-84 $(\mathrm{a}=6378137.00 \mathrm{~m}, \mathrm{~b}=6356752.314 \mathrm{~m})$ (M.J. Merrigan and others 2002; NIMA 2000) on the flat surface using the Gauss-Krüger transformation, which is widely used in geodesy. The calculations obtained the plane coordinates $(x, y)$, where the $x$ value means the distance (in meters) from the Equator to a point measured along the meridian arc (on a rotated ellipsoid WGS-84), and the variable y value is the distance from the central meridian, which is arbitrarily set. The negative sign (minus) indicates that the point is located west of the meridian, while a positive sign (plus) corresponds to the position east of the meridian. In order to avoid the negative values for the $y$-axis coordinate the result is often added to a fixed value of 


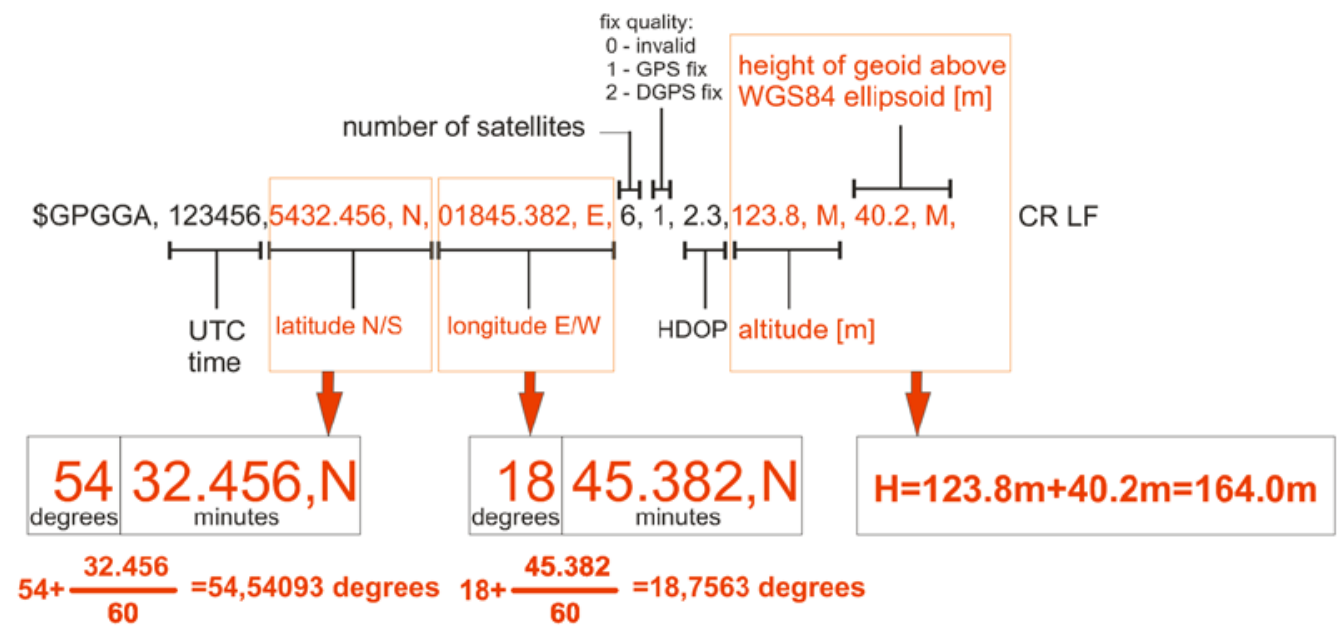

Fig. 3. Message Description GGA NMEA standard. An example of calculating latitude and height above MSL, based on GGA data
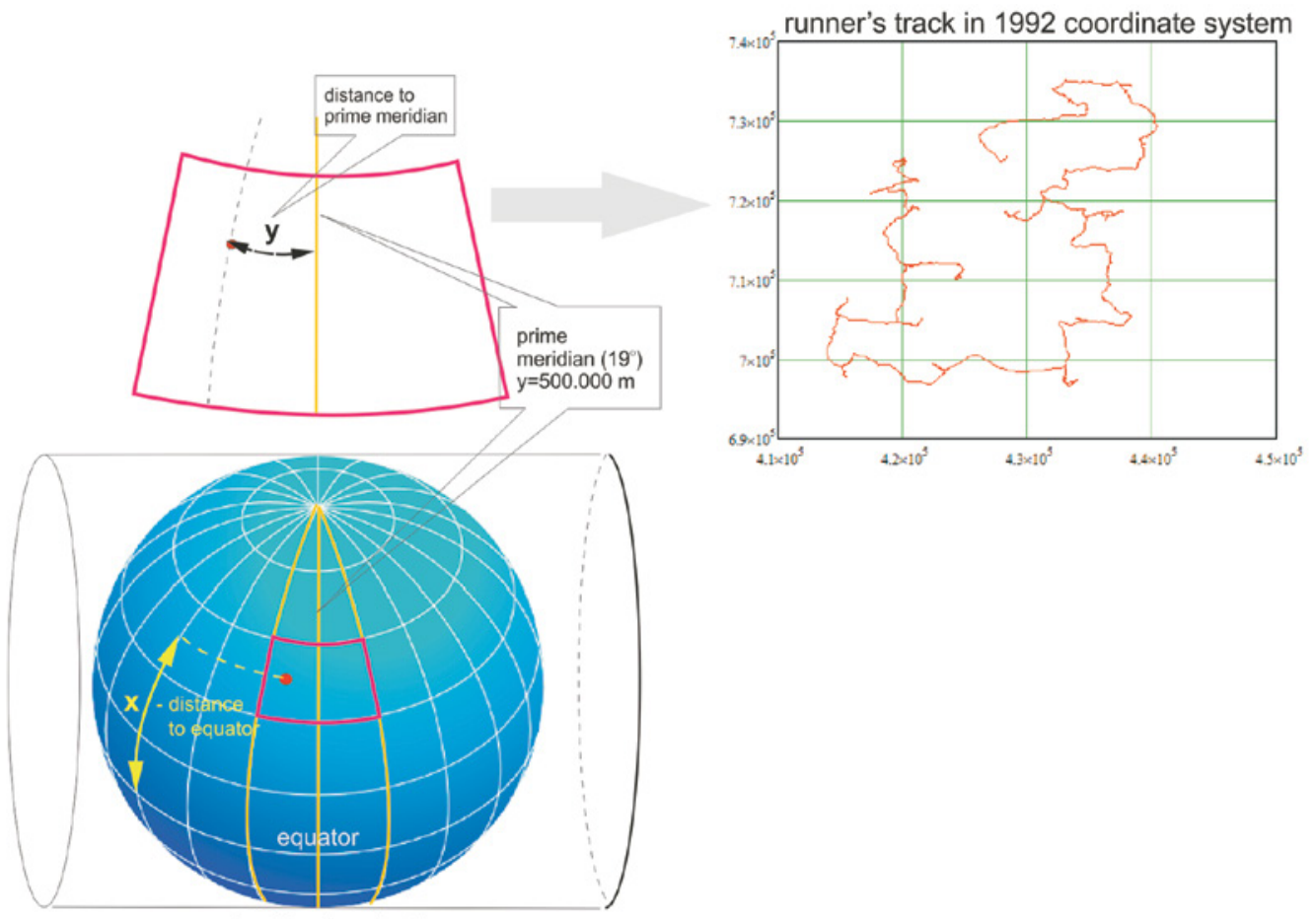

cylindrical projection

Fig. 4. Essence of Gauss-Krüger projection with a sample map and an applied route of an athlete 
e.g. $500,000 \mathrm{~m}$ (for the three-stage zone of the mapping system 2000). It is acceptable also to use the system 1992 to implement this type of calculation. The essence of Gauss-Krüger mapping (the mapping system 1992) is shown in the figure 4.

In the referred studies the system 2000 was used, but the conversion of angular coordinates to the Cartesian ones was implemented based on the relations shown below (R.E. Deakin and others 2010): in the previous section), a spreadsheet within the software Mathcad 15 was created, it marked those values automatically. The following tables summarize the results of the evaluation of positioning accuracy measurement for the systems DGPS and EGNOS.

Within the research works it was also made the analysis of a random variable, which is an error of a single measurement in terms of typical statistics used in navigation. The statistical distribution of determining the position may be

$$
\begin{aligned}
& x=k \cdot R \cdot\left[\frac{S(B)}{R}+\frac{(\Delta L)^{2}}{2} \cdot \sin (B) \cdot \cos (B)+\frac{(\Delta L)^{4}}{24} \cdot \sin (B) \cdot \cos ^{3}(B) \cdot\left(5-t^{2}+9 \cdot \eta^{2}+4 \cdot \eta^{4}\right)+\right. \\
& +\frac{(\Delta L)^{6}}{720} \cdot \sin (B) \cdot \cos ^{5}(B) \cdot\left(61-58 \cdot t^{2}+t^{4}+270 \cdot \eta^{2}-330 \cdot \eta^{2} \cdot t^{2}+445 \cdot \eta^{4}\right] \\
& y=R \cdot\left[\Delta L \cdot \cos (B)+\frac{(\Delta L)^{3}}{6} \cdot \cos ^{3}(B) \cdot\left(1-t^{2}+\eta^{2}\right)+\frac{(\Delta L)^{5}}{120} \cdot \cos ^{5}(B) .\right. \\
& \left.\cdot\left(5-18 \cdot t^{2}+t^{4}+14 \cdot \eta^{2}-58 \cdot \eta^{2} \cdot t^{2}+13 \cdot \eta\right)\right]
\end{aligned}
$$

where:

$B, L-$ measured ellipsoidal coordinates;

$R$ - radius of curvature in the prime vertical;

$S(B)$ - distance from the Equator to defined coordinate B [m];

$\Delta \mathrm{L}$ - difference in longitude between $\mathrm{L}$ and Prime Meridian [m];

$\mathrm{k}$ - scale factor of 0.999923 ,

the other parameters of mapping for the plane coordinates in the system 2000 were:

$$
t=\tan (B) \text { and } \eta=\frac{e^{2} \cdot \cos ^{2}(B)}{1-e^{2}}
$$

where:

e - first eccentricity of ellipsoid;

$\eta$ - orientation angle of distortion ellipse.

The processing of the results for all campaigns was implemented in the software Mathcad 15, the first step of which was to convert the coordinates $B, L$ do $x, y$.

\subsection{Findings}

For the evaluation of the statistical values of individual measurement accuracy (presented presented by the Rayleigh distribution in the form of a probability density function $f(x ; \sigma)$ and cumulative distribution $F(x)(H$. Śniegocki and others 2014):

$$
f(x ; \sigma)=\frac{x}{\sigma^{2}} e^{\frac{-x^{2}}{2 \sigma^{2}}} \text { and } F(x)=1-e^{\frac{-x^{2}}{2 \sigma^{2}}}
$$

For $x \in[0, \infty)$, wherein the scale parameter $\sigma$ is defined as: równanie jak $w$ oryginale

$$
\sigma=\sqrt{\frac{1}{2 N} \sum_{i=1}^{N} x_{i}^{2}}
$$

where:

$\mathrm{N}$ - number of measurements.

Assessing in a comparative manner both systems (DGPS and EGNOS), the cumulative distribution functions of the Rayleigh distribution are presented in the figures 5 and 6 .

Assessing in a comparative manner both of the systems (DGPS and EGNOS), the probability density function of the Rayleigh distribution is presented in the figures 7 and 8 . 


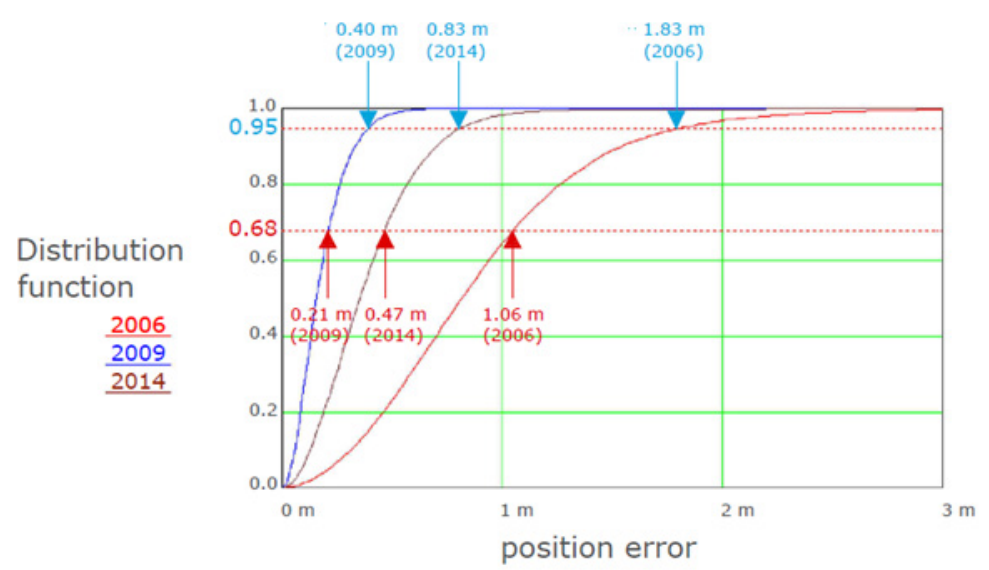

Fig. 5. DGPS horizontal position error (relative to the true position) distribution function calculated for campaigns in 2006, 2009 and 2014

\section{Distribution function} 2006

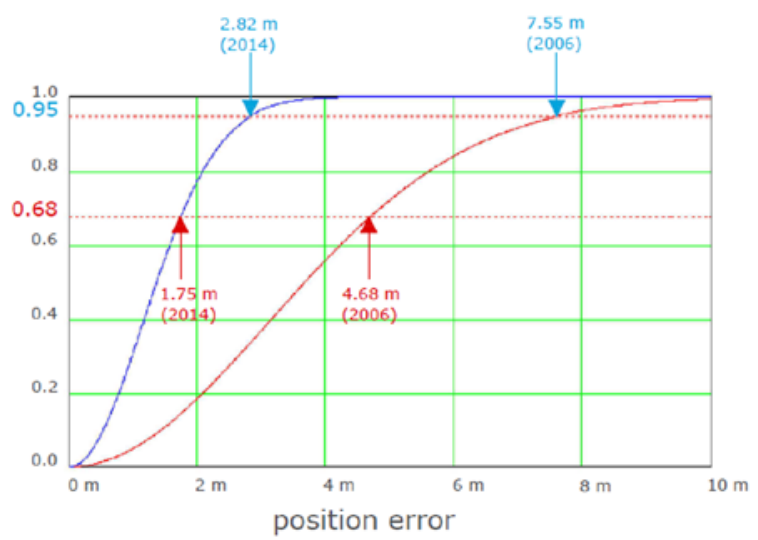

Fig. 6. EGNOS horizontal position error (relative to the true position) distribution function calculated for campaigns in 2006 and 2014

\section{Conclusion}

The analysis of the research findings showed, that the distributions of error of 2D position, which was predictable for DGPS during the campaign of the years 2009 and 2014, were respectively $0.40 \mathrm{~m}$ and $0.83 \mathrm{~m}$, but for the campaign of $2006-1.83 \mathrm{~m}(\mathrm{p}=0.95)$. Since 2009 more technologically advanced GPS receivers have been used. These receivers form the basic element of the reference station. The differences, previously mentioned, resulted mainly from that very application (2009) of more advanced receivers. Moreover, in the case of differential systems a significant impact on getting the positioning accuracy has the distance, that separates a receiver from the reference station. The tests were performed in a relatively short distance from the station $(40 \mathrm{~km})$, this resulted in a high level of signal strength $(52 \mathrm{~dB} \mu \mathrm{V} / \mathrm{m})$ and signal-to-noise ratio (20 dB) (H. Śniegocki and others 2014). According to the standard issued by IALA (2004), the accuracy in the horizontal plane, that the differential system must ensure, is $10 \mathrm{~m}(\mathrm{p}=0.95)$. In view of the above, it is clear, that Polish 


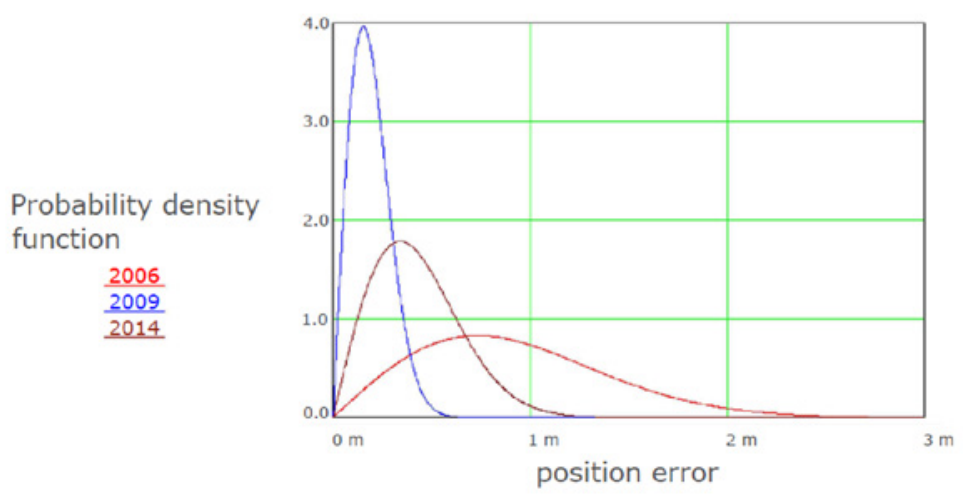

Fig. 7. Probability density function (Rayleigh distribution) for position error of the DGPS for campaigns in 2006, 2009 and 2014

\section{Probability density function

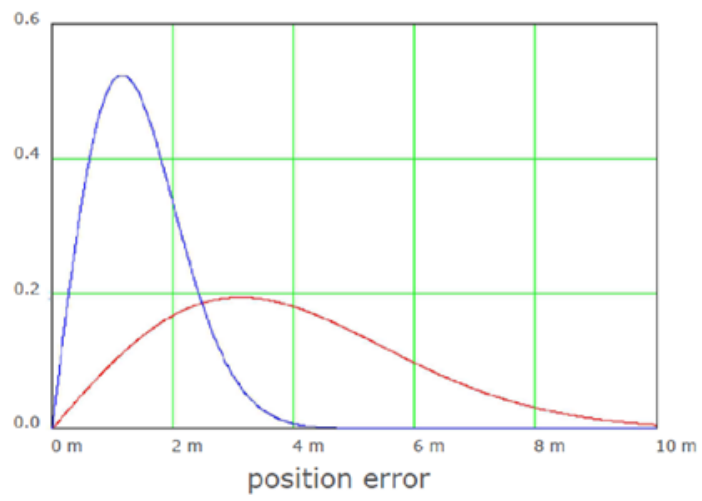

Fig. 8. Probability density function (Rayleigh distribution) for position error of the EGNOS for campaigns in 2006 and 2014

DGPS can be used in the navigation of ships approaching the port, as well as in the coastal shipping, hydrography, sea resource exploration, it can support the work of the systems for Vessel Traffic Service (VTS), as well as Automatic Identification System (AIS). Based on the accuracy of positioning the coordinates, it can be concluded, that EGNOS system is characterized by a slightly worse characteristics of accuracy than DGPS. The statistics of error of 2D position for EGNOS during the campaign of 2014 amounted to $2.82 \mathrm{~m}$, while the campaign of 2006 reached $7.55 \mathrm{~m}(\mathrm{p}=0.95)$. It should be noted, that the launch of the fully operational EGNOS Open Service resulted in a significant increase of its accuracy, which is confirmed by the measurements made in 2014. In accordance with the requirements, the accuracy of EGNOS should not be greater than $3 \mathrm{~m}$ in the horizontal plane, and $4 \mathrm{~m}$ in the vertical plane ( $p=0.95$ ) (DG ENTR 2014). As demonstrated by the research works in Gdynia, EGNOS system fulfils the abovedescribed requirements for a precision and therefore can be used, among others, in the selected applications of civil aviation, maritime and land navigation. 


\section{References}

Bailey B.K., 2014, GPS Modernization Update \& Program Plans. Proceedings of the 13th Meeting of National Space-Based Positioning, Navigation, and Timing Advisory Board.

Deakin R.E., Hunter M.N., Karney C.F.F., 2010, The Gauss-Krüger Projection. Proceedings of the 23rd Victorian Regional Survey Conference.

DG ENTR, 2014, EGNOS Open Service (OS) - Service Definition Document. Revision 2.1.

Dziewicki M., Specht C., 2009, Position Accuracy Evaluation of the Modernized Polish DGPS. „Polish Maritime Research" Vol. 16, issue 4, pp. 57-61.

Grall P., Specht C., 2011, Ocena porównawcza standardów SPS systemu GPS w aspekcie dokładności określenia pozycji. „Zeszyty Naukowe AMW” no. 3 (186), pp. 43-56.

IALA, 2004, Recommendation R-121 on the Performance and Monitoring of DGNSS Services in the Frequency Band 283.5 - $325 \mathrm{kHz}$. Edition 1.1.

Merrigan M.J., Swift E.R., Wong R.F., Saffel J.T., 2002, A Refinement to the World Geodetic System 1984 Reference Frame. Proceedings of the 15th International Technical Meeting of the Satellite Division of The Institute of Navigation, pp. 1519-1529.

Mięsikowski M., Nowak A., Specht C., Oszczak B., 2006, EGNOS - Accuracy Performance in Poland. „Annual of Navigation” no. 11, pp. 63-72.

NIMA, 2000, Department of Defense World Geodetic System 1984, Its Definition and Relationships with Local Geodetic Systems. 3rd Edition.

NovAtel Positioning Leadership, 2003, GPS Position Accuracy Measures. APN-029 Revision 1.
Specht C., 2007a, DGPS and EGNOS Systems in Hydrographic Survey - Accuracy Analyses at the Polish Sea Area. „Hydroacoustics” Vol. 10, pp. 193-198.

Specht C., 2007b, System GPS. Pelplin: Wydawnictwo Bernardinum.

Specht C., 2011, Accuracy and Coverage of the Modernized Polish Maritime Differential GPS. „Advanced in Space Research" Vol. 47, issue 2, pp. 221-228.

Specht C., Mania M., Specht M., Skóra M., 2015, Accuracy of the GPS Positioning System in a Context of Increasing the Number of Satellites in the Constellation. „Polish Maritime Research” Vol. 22, issue 2, pp. 9-14.

Śniegocki H., Specht C., Specht M., 2014, Testing Accuracy of Maritime DGPS System Based on Long-Term Measurements Campaigns Over the Years 2006-2014. „International Journal of Civil Engineering and Technology" Vol. 5, issue 10, pp. 1-8.

U.S. DoD, 2008, Global Positioning System. Positioning Service Performance Standard. 4th Edition.

U.S. DoD, U.S. DHS, U.S. DoT, 2012, 2012 Federal Radionavigation Plan.

Van Diggelen F., 2007, GNSS Accuracy - Lies, Damn Lies and Statistics. „GPS World” Vol. 18, no. 1, pp. 27-32.

Wang Y., Li R., 2013, The Analysis of Character of User Range Accuracy. „Lecture Notes in Electrical Engineering" Vol. 244, pp. 267-277.

Whelan B., Taylor J., 2013, Precision Agriculture for Grain Production Systems. Clayton: CSIRO Publishing. 